\title{
DFNB44, a Novel Autosomal Recessive Non-Syndromic Hearing Impairment Locus, Maps to Chromosome 7p14.1-q11.22
}

\author{
Muhammad Ansar a Maria H. Chahrour ${ }^{\mathrm{b}}$ Mohammad Amin ud Din ${ }^{\mathrm{c}}$ \\ Muhammad Arshad a Sayedul Haquea Thanh L. Pham ${ }^{b}$ Kai Yan ${ }^{b}$ \\ Wasim Ahmada Suzanne M. Leal ${ }^{b}$ \\ aDepartment of Biological Sciences, Quaid-I-Azam University, Islamabad, Pakistan; b Department of Molecular and \\ Human Genetics, Baylor College of Medicine, Houston, Tex., USA; ' Government Degree College, DG Khan, \\ Pakistan
}

\section{Key Words}

7p14.1-q11.22 · DFNB44 • Non-syndromic hearing

impairment $\cdot$ Pakistan

\begin{abstract}
The genetic etiology for many forms of hearing impairment $(\mathrm{HI})$ is very diverse. Non-syndromic $\mathrm{HI}$ (NSHI) is one of the most heterogeneous traits known. Autosomal recessive forms of prelingual $\mathrm{HI}$ account for $\sim 75 \%$ of hereditary cases. A novel autosomal recessive NSHI locus, DFNB44, was mapped to a 20.9 cM genetic interval on chromosome 7p14.1-q11.22, according to the Marshfield genetic map, in a consanguineous Pakistani family. Multipoint linkage analysis resulted in a maximum LOD score of 5.0 at marker D7S1818. The 3-unit support interval ranged from marker D7S2209 to marker D7S2435, spanning a $30.1 \mathrm{Mb}$ region on the sequence-based physical map.
\end{abstract}

Copyright $\odot 2004$ S. Karger AG, Basel

\section{Introduction}

Hereditary hearing impairment (HI) that is not associated with any other clinical feature, syndrome, or disorder, is termed non-syndromic. Approximately 75\% of non-syndromic HI (NSHI) cases with a genetic etiology display an autosomal recessive mode of inheritance. Autosomal dominant forms are observed in $15 \%$ of cases, while mitochondrial and X-linked NSHI are less frequent [1]. Autosomal recessive NSHI is generally due to a sensorineural defect [2], is manifested at the prelingual stage, and is severe to profound, affecting all frequencies. NSHI is an extremely heterogeneous trait, with over 40 loci mapped for autosomal recessive forms and 18 genes isolated [3]. This heterogeneity is largely due to the complexity of the inner ear, and the various mechanisms that can lead to the HI phenotype [4]. A consanguineous Pakistani family segregating a novel autosomal recessive NSHI locus, DFNB44, is described. This locus was mapped to a $20.9 \mathrm{c} M$ region on chromosome $7 \mathrm{p} 14.1-\mathrm{q} 11.22$.

\section{Materials and Methods}

\section{Family History}

Approval was obtained from the Quaid-I-Azam University Institutional Review Board prior to the onset of the study. Informed consent was obtained from all family members who participated in the study. A consanguineous family from Pakistan was ascertained. Information obtained during interviews with multiple family members was used to construct the pedigree and to clarify consanguineous relationships. HI displayed an autosomal recessive mode of inheritance in pedigree 4009 (fig. 1). Affected individuals present with prelingual profound $\mathrm{HI}$ which affects all frequencies and is probably

\begin{tabular}{ll}
\hline KARGER & ( 2004 S. Karger AG, Basel \\
Fax +41613061234 & \\
$\begin{array}{l}\text { E-Mail karger@karger.ch } \\
\text { www.karger.com }\end{array}$ & $\begin{array}{l}\text { Accessible online at: } \\
\text { www.karger.com/hhe }\end{array}$
\end{tabular}

Dr. Suzanne M. Leal

Department of Molecular and Human Genetics

Baylor College of Medicine, One Baylor Plaza

Alkek Building N1619.01, Houston, TX 77030 (USA)

Tel. +1 713798 4011, Fax +1 713798 4373, E-Mail sleal@bcm.tmc.edu 


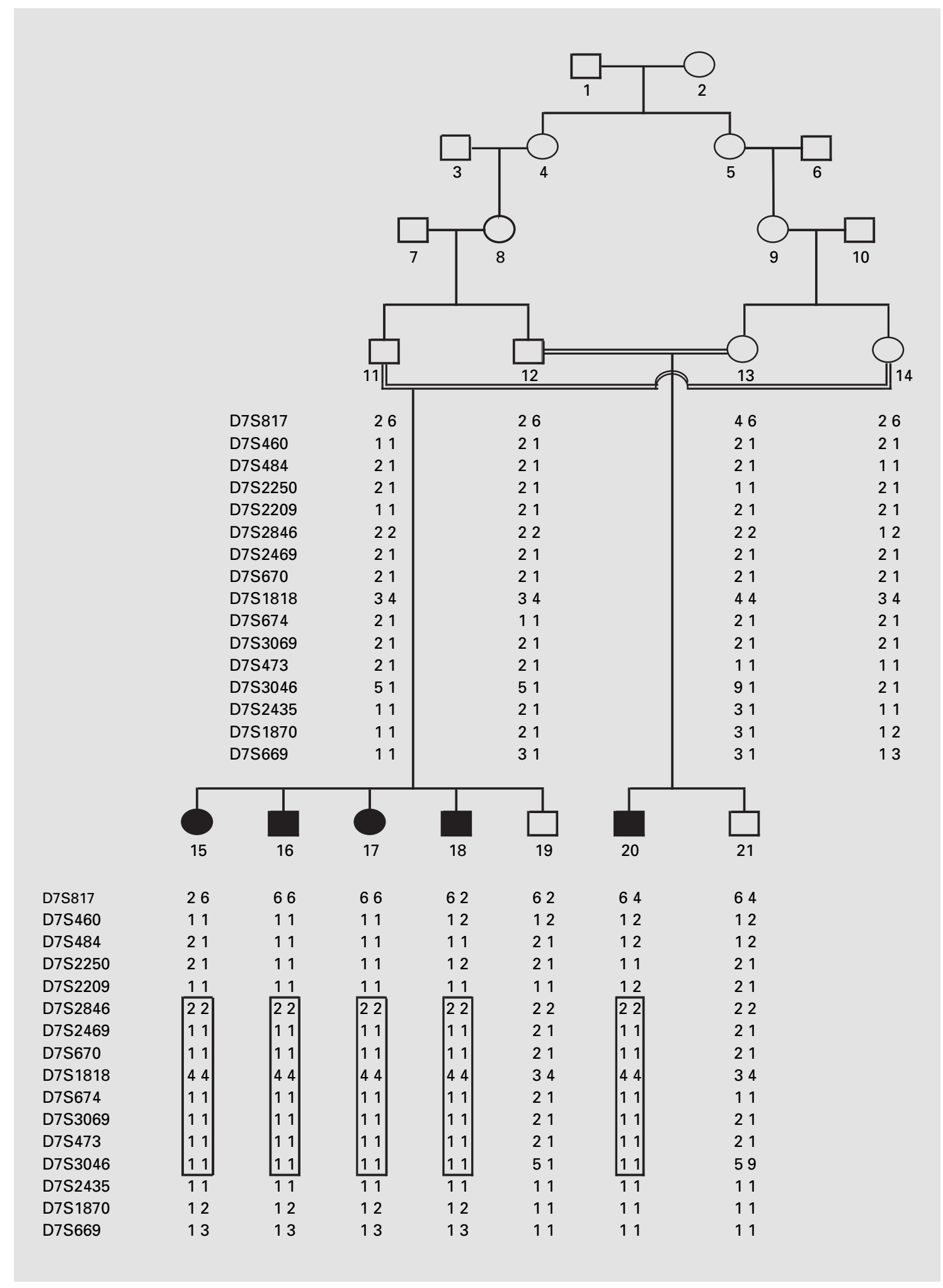

Fig. 1. Drawing of pedigree 4009 that segregates DFNB44. The sexes of some of the family members have been changed to protect the anonymity of the family. Black symbols represent individuals with hearing impairment due to DFNB44. Clear symbols represent unaffected individuals. Haplotypes for the most closely linked STRs are shown below each symbol. The haplotype for DFNB44 is displayed in a box. 
Table 1. Two-point LOD score results between DFNB44 and chromosome 7 markers

\begin{tabular}{|c|c|c|c|c|c|c|c|c|c|c|}
\hline \multirow[t]{2}{*}{ Marker } & \multirow{2}{*}{$\begin{array}{l}\text { Marshfield } \\
\text { map } \\
\text { position }^{\text {a }}\end{array}$} & \multirow{2}{*}{$\begin{array}{l}\text { deCode } \\
\text { map } \\
\text { position }^{b}\end{array}$} & \multirow{2}{*}{$\begin{array}{l}\text { Physical } \\
\text { map } \\
\text { position }^{c}\end{array}$} & \multicolumn{7}{|c|}{ LOD score at $\theta=$} \\
\hline & & & & 0.0 & 0.02 & 0.04 & 0.05 & 0.1 & 0.2 & 0.3 \\
\hline D7S817 & 50.29 & 52.16 & 31878592 & $-\infty$ & -0.06 & 0.41 & 0.54 & 0.81 & 0.76 & 0.48 \\
\hline D7S460 & - & 54.15 & 34035346 & $-\infty$ & -1.13 & -0.62 & -0.47 & -0.08 & 0.12 & 0.10 \\
\hline D7S484 & 53.50 & 54.65 & 35027091 & $-\infty$ & -1.37 & -0.84 & -0.68 & -0.25 & 0.01 & 0.04 \\
\hline D7S2250 & 54.11 & 54.65 & 35120620 & $-\infty$ & -0.65 & -0.16 & -0.02 & 0.32 & 0.41 & 0.27 \\
\hline$D 7 S 2209$ & 57.79 & 58.84 & 37300642 & -2.13 & 0.04 & 0.27 & 0.33 & 0.46 & 0.42 & 0.26 \\
\hline D7S2846 & 57.79 & 59.12 & 37875515 & 1.36 & 1.29 & 1.22 & 1.19 & 1.02 & 0.69 & 0.38 \\
\hline D7S2469 & 61.53 & 62.34 & 40864239 & 3.11 & 2.97 & 2.83 & 2.76 & 2.41 & 1.70 & 0.98 \\
\hline D7S670 & 69.56 & 69.46 & 46909751 & 3.11 & 2.97 & 2.83 & 2.76 & 2.41 & 1.70 & 0.98 \\
\hline D7S1818 & 69.56 & 70.71 & 49133606 & 2.52 & 2.41 & 2.29 & 2.24 & 1.95 & 1.37 & 0.81 \\
\hline D7S674 & 70.64 & 71.27 & 49284035 & 2.55 & 2.44 & 2.32 & 2.27 & 1.98 & 1.39 & 0.80 \\
\hline D7S3069 & 73.31 & 74.74 & 52023510 & 3.11 & 2.97 & 2.83 & 2.76 & 2.41 & 1.70 & 0.98 \\
\hline D7S473 & 76.71 & 78.13 & 57153928 & 1.95 & 1.86 & 1.77 & 1.73 & 1.51 & 1.08 & 0.65 \\
\hline D7S3046 & 78.65 & - & 67964439 & 4.48 & 4.32 & 4.15 & 4.07 & 3.64 & 2.73 & 1.77 \\
\hline$D 7 S 2435$ & 80.42 & 81.88 & 68477387 & $-\infty$ & -0.55 & -0.30 & -0.23 & -0.06 & 0.01 & 0.01 \\
\hline D7S1870 & 86.12 & 86.89 & 73538645 & $-\infty$ & -1.40 & -0.85 & -0.68 & -0.22 & 0.08 & 0.10 \\
\hline D7S669 & 90.42 & 89.39 & 77484487 & $-\infty$ & -0.88 & -0.46 & -0.32 & 0.03 & 0.20 & 0.15 \\
\hline
\end{tabular}

Genome scan markers are shown in bold. Markers in italics flank the haplotype.

Sex-averaged kosambi cM map distance from the Marshfield genetic map [8].

Sex-averaged kosambi cM map distance from the deCode genetic map [16].

Sequence-based physical map distance in bases according to Human Genome Project - Santa Cruz [12].

congenital. The hearing impaired individuals in this pedigree use sign language for communication. Hearing impaired individuals underwent a physical examination, and no clinical features, including mental retardation, that would indicate that the HI was part of a syndrome, were observed. In addition, no gross vestibular involvement was observed.

\section{Extraction of Genomic DNA and Genotyping}

Venous blood samples were collected from a total of 11 individuals, including 5 who are hearing impaired. Genomic DNA was extracted from whole blood following a standard protocol [5], quantified by spectrophotometric readings at optical density 260 , and diluted to $40 \mathrm{ng} / \mu \mathrm{l}$ for PCR amplification. A genome scan was carried out on all the DNA samples at the Center for Inherited Disease Research (CIDR). A total of 388 fluorescently labeled short tandem repeat (STR) markers were genotyped. These markers are spaced $\sim 10 \mathrm{cM}$ apart and are located on the 22 autosomes and the $\mathrm{X}$ and $\mathrm{Y}$ chromosomes.

\section{Linkage Analysis}

Two-point linkage analysis was carried out on all autosomal markers from the genome scan using the MLINK program of the FASTLINK computer package [6]. Multipoint linkage analysis was performed using ALLEGRO [7] with map distances from the Marshfield genetic map [8]. Haplotypes were constructed using SIMWALK2 $[9,10]$. An autosomal recessive mode of inheritance with complete penetrance and a disease allele frequency of 0.001 were used for the analysis. For the genome scan markers, allele frequencies were estimated from the founders and reconstructed genotypes of founders from pedigree 4009 and thirteen additional pedigrees that underwent a genome scan at CIDR at the same time. Equal allele frequencies were used for the fine mapping markers, because it was not possible to estimate allele frequencies from the founders, since these markers were only genotyped in this family. A sensitivity analysis was carried out in order to evaluate whether a false positive result had occurred due to using incorrect allele frequencies [11]. Multipoint linkage analysis was performed by varying the allele frequency for the allele segregating with the disease allele from 0.2 to 0.8 for the fine mapping markers.

\section{Results}

Two-point linkage analysis of the genome scan markers gave a maximum LOD score of $4.5(\theta=0)$ at marker D7S3046. The maximum multipoint LOD score for the genome scan markers was 4.9 , and it also occurred at marker D7S3046. In order to fine map the region on chromosome 7 and establish linkage, 12 additional microsatellite markers were selected from the Marshfield genetic map [8]. Two-point and multipoint linkage analyses were repeated after genotyping the family members with the 
fine mapping markers. The maximum two-point LOD score remained at marker D7S3046 with a value of 4.5 $(\theta=0)$ (table 1). Multipoint linkage analysis resulted in a maximum LOD score of 5.0 at marker D7S1818. When the marker allele frequencies were varied from 0.2 to 0.8 for the fine mapping markers, the maximum multipoint LOD score remained at marker D7S1818 with a value of 5.0. The 3-unit support interval ranged from marker D7S2209 to marker D7S2435, spanning $20.9 \mathrm{c} M$ according to the Marshfield genetic map [8]. The interval corresponds to a $30.1 \mathrm{Mb}$ region on the sequence-based physical map [12]. Haplotypes were then constructed to determine the critical linkage interval. The region of homozygosity was the same as the 3-unit support interval; flanked by markers D7S2209 and D7S2435. The centromeric boundary of the co-segregating interval was defined by a historic recombination event between markers D7S2209 and D7S2846, which was observed in affected individual 20 (fig. 1). Unaffected individual 21 was homozygous at marker D7S2435, and since unaffected individuals 12 and 13 (parents of individual 21) were heterozygous at marker D7S2435, the telomeric boundary of the interval was set at marker D7S3046.

\section{Discussion}

The NSHI locus DFNB44 was mapped to a $20.9 \mathrm{c} M$ region on chromosome 7p14.1-q11.22, according to the Marshfield genetic map [8], in a consanguineous Pakistani kindred. Five loci for autosomal recessive NSHI have previously been localized on chromosome 7, DFNB4 (7q31), DFNB13 (7q34-q36), DFNB14 (7q31), DFNB17 (7q31) and DFNB39 (7q11.22-q21.12). Only the gene for DFNB4, SLC26A4, has been identified [3]. The genetic interval for DFNB44 does not overlap with the region for DFNB39 [13]. For many of the known NSHI loci only one pedigree has been ascertained world wide. Although these pedigrees are large enough to independently establish linkage, due to the limited number of meioses within each pedigree the genetic region for the NSHI locus is often large making gene identification difficult due to the large number of genes within a given region.

To date, more than 80 known, and 21 predicted, genes have been localized to the DFNB44 region [12]. Several of these genes are expressed in the cochlea, and are potential candidates for DFNB44. A potential candidate is the $\beta$-glucuronidase gene (GUSB, MIM 253220). GUSB codes for the $\beta$-glucuronidase enzyme, and maps to chromosome 7q11.21. Mutations in this gene are associated with mucopolysaccharidosis type VII (MPS VII, MIM 253220), a lysosomal storage disease caused by dysfunction of $\beta$-glucuronidase, resulting in the accumulation of incompletely degraded glycosaminoglycans within lysosomes of various cell types [14]. One of the characteristics of MPS VII is mixed (conductive and sensorineural) hearing loss. In addition, affected patients manifest skeletal abnormalities, vision defects, mental retardation and a decreased lifespan [14]. Moreover, MPS VII mice present with severe pathologic abnormalities in many ear structures, which could account for the hearing impairment similar to that observed in affected humans [15]. The exons and promoter region of the GUSB gene were screened for mutations in two hearing impaired and one unaffected family member. The GUSB gene was excluded as being the underlying gene for DFNB44. Identification of the gene for DFNB44 will enhance our understanding of the molecular mechanisms of the auditory system, as well as those involved in the etiology of NSHI.

\section{Acknowledgements}

We wish to thank the family members for their invaluable participation and cooperation. This work was supported by the Higher Education Commission (HEC), Pakistan and the NIH National Institute of Deafness and other Communication Disorders grant DC03594. Genotyping services were provided by the Center for Inherited Disease Research (CIDR). CIDR is fully funded through a federal contract from the National Institutes of Health to The Johns Hopkins University, Contract Number N01-HG-65403.
$198 \quad$ Hum Hered 2004;57:195-199
Ansar/Chahrour/Amin ud Din/Arshad/ Haque/Pham/Yan/Ahmad/Leal 


\section{References}

1 Morton NE: Genetic epidemiology of hearing impairment. Ann N Y Acad Sci 1991;630:1631.

2 Petit C: Genes responsible for human hereditary deafness: Symphony of a thousand. Nat Genet 1996;14:385-391.

3 Van Camp G, Smith RJH: Hereditary Hearing Loss Homepage. 2003. URL: http://www. uia.ac.be/dnalab/hhh.

$>4$ Steel KP, Bussoli TJ: Deafness genes: expressions of surprise. Trends Genetics 1999;15: 207-211.

$\checkmark 5$ Grimberg J, Nawoschik S, Bellusico L, McKee R, Turck A, Eisenberg A: A simple and efficient non-organic procedure for the isolation of genomic DNA from Blood. Nucleic Acid Res 1989; $17: 8390$.

6 Cottingham R, Indury RM, Schaffer AA: Faster sequential genetic linkage computations. Am J Hum Genet 1993;53:252-263.
7 Gudbjartsson DF, Jonasson K, Frigge ML, Kong A: Allegro, a new computer program for multipoint linkage analysis. Nat Genet 2002; 25:12-13.

8 Broman K, Murray JC, Scheffield VC, White RL, Weber JL: Comprehensive human genetic maps: Individual and sex specific variation in recombination. Am J Hum Genet 1998;63: 861-869.

9 Weeks DE, Sobel E, O'Connell JR, Lange K: Computer programs for multilocus haplotyping of general pedigrees. Am J Hum Genet 1995;56:1506-1507.

10 Sobel E, Lange K: Descent graphs in pedigree analysis: Applications to haplotyping, location scores, and marker-sharing statistics. Am J Hum Genet 1996;58:1323-1337.

11 Freimer NB, Sandkuijl LA, Blower SM: Incorrect specification of marker allele frequencies: effects on linkage analysis. Am J Hum Genet 1993;52:1102-1110

12 International Human Genome Sequence Consortium: Initial sequence and analysis of the human genome. Nature 2001;409:860-921.
13 Wajid M, Abbasi AA, Ansar M, Pham TL, Yan K, Haque S, Ahmad W, Leal SM: DFNB39, a recessive form of sensorineural hearing impairment, maps to chromosome 7q11.22-q21.12. Euro J Hum Genet 2003; 11:812-815.

4 Ohlemiller KK, Hennig AK, Lett JM, Heidbreder AF, Sands MS: Inner ear pathology in the mucopolysaccharidosis VII mouse. Hearing Res 2002;169:69-84.

5 Sands MS, Erway LC, Vogler C, Sly WS, Birkenmeier EH: Syngeneic bone marrow transplantation reduces the hearing loss associated with murine mucopolysaccharidosis type VII. Blood 1995;86:2033-2040.

16 Kong A, Gudbjartsson DF, Sainz J, Jonsdottir GM, Gudjonsson SA, Richardsson B, Sigurdardottir S, Barnard J, Hallbeck B, Masson G, Shlien A, Palsson ST, Frigge ML, Thorgeirsson TE, Gulcher JR, Stefansson K: A high-resolution recombination map of the human genome. Nat Genet 2002;31:241-247. 